\title{
REFLECTED AND MINOR PHASES IN RECORDS OF NEAR-BY EARTH- QUAKES IN SOUTHERN CALIFORNIA*
}

\author{
By B. Gutenberg
}

\section{INTRODUCTION}

THE PRESENT paper is a direct continuation of a recent paper (Gutenberg, 1944a) in which the author has discussed travel times of the major $\mathrm{P}$ and $\mathrm{S}$ phases recorded at near-by stations for fifty southern California earthquakes. To facilitate the present investigation of phases complicated by refraction and reflection, thorough consideration was given to the partition of energy into the various reflected and refracted waves at discontinuities and to the ratio of ground displacements to the incident amplitudes at the surface of the earth (Gutenberg, 1944b). This seems desirable since the number of theoretically possible phases to be expected is very large, considering the four layers in the earth's crust; consequently, any calculated curve can be "verified" by using small impulses to be found on most seismograms. Therefore, clearly recognizable phases should be used in such investigations, and only calculated travel times for waves with amplitudes theoretically large enough to be conspicuous.

The purpose of the present paper is to present the study of travel times of phases on seismograms from southern California earthquakes recorded within $900 \mathrm{~km}$. from the source which fulfill these conditions but which have not been investigated in the paper mentioned above. The material used has been described previously (Gutenberg, 1943b, 1944a).

After combining measurements of the same phase on different components, phases measured on the seismograms total roughly 6,000 . On the average there are 11.4 stations for each of the fifty shocks; consequently, about ten readings from each station are used for an average shock. In a later survey only the really outstanding phases were once more measured, reducing the total by about 25 per cent. All readings were plotted on a travel-time curve diagram having a scale for distance of $1 / 2 \mathrm{~cm}$. for $1 \mathrm{~km}$., and for time of $1 \mathrm{~cm}$. per sec. This plot, composed of several sheets for distances up to $600 \mathrm{~km}$., covers about 9 by 6 feet. As its reproduction on a small scale is not practicable, it was decided to reproduce only four important and characteristic sections showing observations on a reduced scale (figs. 1 to 4 ). ${ }^{1}$ It must be clearly understood that all these plots refer to a region in which conditions are considered unique (Gutenberg, 1943a, fig. 2, p. 483) and therefore are examples rather than basic graphs for use in other areas. Figure 7, showing travel-time curves of frequently observed phases but without observations, gives a summary of the results for distances up to $450 \mathrm{~km}$., with indications of amplitudes.

In using the figures, it must be considered that the standard error of one plotted time observation for $\mathrm{P}$ phases is about $1 / 2$ sec., for $\mathrm{S}$ phases about $3 / 4$ sec. This is mainly due to inexact location of the epicenters, errors in the assumed origin time, difficulties in finding the beginning of a phase, especially in the $\mathrm{S}$ waves, and local variations in the velocity along the waves' paths. For this last reason, $\mathrm{Pn}$ and Sn

* Manuscript received for publication September 3, 1943.

1 Figures were drafted by Mr. John M. Nordquist. 
waves traveling partly under the Sierra Nevada or eastern California have not been used in any of the travel-time curves in the present paper. The scattering of the points in these figures often makes it difficult to decide from the plot to which curve a specific point belongs, and casts some doubt upon certain curves. Often, however, such difficulties are easily removed if the aspect of the phases on enlarged copies of the seismograms is considered concurrently with the travel-time curves. For this reason, typical seismograms have been reproduced (figs. 5 and 6). Others may be found in previous publications (Gutenberg, 1932, figs. 8-11; 1943a, pl. 1 and pl. 2, j; note that, in the latter two, $\mathrm{P}^{*}$ is identical with $\mathrm{Py}$ in the present paper.)

$\mathrm{P}=$ longitudinal waves.

SYmbols Used

$\mathrm{S}=$ transverse waves ( $\mathrm{SH}$, with horizontal vibrations only; $\mathrm{SV}$, with horizontal and vertical movements; $\mathrm{SV} \perp \mathrm{P}$, in plane of ray).

$\overline{\mathrm{P}}, \overline{\mathrm{S}}$ indicate direct waves through the "granitic" layer only (neglecting the sediments). Py, Sy refer to direct waves with their deepest point in the "first intermediate layer"; similarly, Pm, Sm, to those in the "second intermediate layer." Pn, Sn are the symbols for the direct waves which have penetrated below the Mohorovičić discontinuity.

It is assumed that all waves start originally at the discontinuity between the granitic and the first intermediate layers. The depth at which a reflection or a change from $P$ to $S$, or vice versa, has taken place is indicated by numerals between the symbols $\mathrm{P}$ or $\mathrm{S}$; for the surface of the earth, the corresponding figure zero is omitted.

The symbols are not ambiguous. Examples may explain the details more readily than a description: for example, "S33P" travels as an S wave from the source (at a depth of $18 \mathrm{~km}$.) down to the depth of $33 \mathrm{~km}$. and there is reflected to the surface as a $\mathbf{P}$ wave. The corresponding wave, refracted at the discontinuity at $33 \mathrm{~km}$. into a $P$ wave and then refracted once more up to the surface (without reaching the next deeper discontinuity at $37 \mathrm{~km}$.), is indicated by "S33P33P." If it descends below the Mohorovičić discontinuity at $37 \mathrm{~km}$., it is written S33P37P37P. Sy $\equiv$ S18S. $\mathrm{Pn} \equiv \mathrm{P} 37 \mathrm{P} 37 \mathrm{P}$.

If paths of reflected waves contain segments corresponding to $\mathrm{Py}$, Sy, Pm, ete., they may be combined with other symbols. SSy $\equiv$ SS18S18S starts upward and is reflected at the surface into an Sy wave (including the $\mathrm{S}$ part from the surface down to $18 \mathrm{~km}$.) ; SySy starts downward as a regular Sy wave, reaches the surface, and is reflected there into a similar path (again including an additional part from the surface down to $18 \mathrm{~km}$. after the reflection). If fully written out, as explained above, its symbol would be S18SS18S18S.

Velocities are given by $V$ (longitudinal) and $v$ (transverse) in $\mathrm{km} / \mathrm{sec}$. The angles of incidence are $i$ and $j$, respectively. $\sigma$ indicates Poisson's ratio; $\rho$, the density; $\mu$, the rigidity; and $k$, the bulk modulus in dynes per $\mathrm{cm}^{2}$. The subscripts $1,2,3$, and 4 refer to (1) the granitic, (2) first, and (3) second intermediate layers, and (4) the region below the Mohorovičic discontinuity. In general it is assumed that within each layer the velocities and the angles of incidence are constant; the actual small variations, as well as the curvature of the earth, are neglected. 
$t=$ travel times in seconds

$\Delta=$ epicentral distance in $\mathrm{km}$. measured along the surface of the earth.

$$
\mathrm{Pm}, \mathrm{Sm}
$$

In the investigation of the "principal" $\mathrm{P}$ and $\mathrm{S}$ phases (Gutenberg, 1944a), the phase indicated by "Pm" (Gutenberg, 1932) was not included, since it was considered that Pm might turn out to be due to a reflected wave. However, careful study Jeft little doubt that it is produced by a direct wave (see figs. $3 ; 6$, c and $d$ ). As a consequence of its proximity to the larger Py and of the fact that its amplitudes de-

\section{TABLE 1}

Apparent Velocity $V$ of $\mathbf{P m}$, Intercept Times $a$ (Seconds), Their Standard Errors and Deviations from Average

$n=$ Number of observations used. For identification numbers of shocks, col. 1, see Gutenberg, $1944 a$, table 1.

\begin{tabular}{|c|c|c|c|c|c|c|c|c|}
\hline \multirow{2}{*}{ Shock no. } & \multirow{2}{*}{$n$} & \multirow{2}{*}{ Range of $\Delta$} & \multirow{2}{*}{$V$} & \multirow{2}{*}{$a$} & \multicolumn{2}{|c|}{ Standard error } & \multicolumn{2}{|c|}{ Deviation } \\
\hline & & & & & V & $a$ & $V$ & $a$ \\
\hline $1,2,4,5,6 \ldots$ & 28 & $\begin{array}{c}\mathrm{km} . \\
254-537\end{array}$ & $\begin{array}{c}\mathrm{km} / \mathrm{sec} \\
6.83\end{array}$ & $\begin{array}{l}\text { sec. } \\
3.2\end{array}$ & 0.09 & 0.7 & -0.12 & $\dot{-1.2}$ \\
\hline 8 to 17 & 39 & $180-576$ & 7.04 & 5.0 & .07 & .5 & +0.09 & +0.6 \\
\hline 18 to 34 . & 30 & $169-566$ & 6.92 & 4.2 & .05 & 4 & -0.03 & -0.2 \\
\hline 36 to 45 . & 23 & $160-552$ & 6.93 & 4.1 & .04 & 3 & -0.02 & -0.3 \\
\hline 46 to 50 . & 18 & $174-546$ & 6.86 & 3.8 & 0.04 & 0.3 & -0.09 & -0.6 \\
\hline I to $50 \ldots$ & 138 & $160-576$ & 6.946 & 4.36 & 0.025 & 0.18 & & \\
\hline
\end{tabular}

crease at rather short distances, depending on the region (for details, see table 4 and Gutenberg, 1944c), the data are less plentiful than for the "major" P phases. The observed travel times were treated as were those for Py, etc., using the method of least squares; the results are given in tabłe 1 . The standard error of one observation is $0.7 \mathrm{sec}$. The differences between the various groups are within the limits of error. Too small a value of $V$ (too great a slope of the travel-time curve) should be correlated with too small a value for $a$; this explains the parallelism in the last two columns of table 1 . In case of actual differences in $V$, it should be expected that $a$ will have a minimum in regions where $V$ has a maximum, unless a greater thickness of the preceding layer compensates the effect of the greater velocity.

For the whole region under consideration it may be assumed that the travel time of $\mathrm{Pm}$ is given by $t=4.4-0.1440 \Delta$.

The phase designated by Sm in the earlier paper (Gutenberg, 1932) is now indicated by Sy (Gutenberg, 1944a), as there is little doubt that it corresponds to Py. In the part of the seismogram where the true $\mathrm{Sm}$ is to be expected, 47 observations at distances between 203 and $549 \mathrm{~km}$. were made, 9 of them in shocks 1 to 6 (see figs. 3,4 , and $6, \mathrm{c}, \mathrm{d}, \mathrm{f}$ ). The data available are insufficient for least squares solutions using data for individual areas. In particular, all data from shocks 1 to 6 are from distances between 319 and $376 \mathrm{~km}$. Two least squares solutions were made, one for all shocks and one for shocks 8 to 50 only. The solutions did not differ significantly. 
The intercept time was the same, $6.9 \pm 0.5 \mathrm{sec}$, in both, and the resulting apparent velocity was $4.102 \pm 0.023 \mathrm{~km} / \mathrm{sec}$. in shocks 8 to $50,4.100 \pm 0.023 \mathrm{~km} / \mathrm{sec}$. using all data. The travel times of Sm thus may be represented by $t=6.9+0.2439 \Delta$. The standard error of one observation of $\mathrm{Pm}$ as well as $\mathrm{Sm}$ is 0.7 sec.

\section{Findings for the Layers in Southern California}

The determination of the velocities and intercept times of the $\mathrm{P}$ or $\mathrm{S}$ waves may be used to find the thicknesses of the various layers. (For equations, see Gutenberg, $1943 a$ ). For $\mathrm{S}$ waves, the effect of the "apparent origin time of S" (GutenbergRichter, 1943) must be considered individually for each phase. Table 2 contains the results, as well as other findings from the study of the fifty shocks.

The total thickness of the layers above the Mohorovicié discontinuity increases

TABLE 2

Thickness $d$ (Km.) and Other Data (She "Stmbols Used") for the Layers in Southern California

$\rho$ is assumed.

\begin{tabular}{|c|c|c|c|c|c|c|}
\hline \multirow{3}{*}{ Datum } & \multicolumn{6}{|c|}{ Layer } \\
\hline & \multirow{2}{*}{ Granitic } & \multirow{2}{*}{ First intermediate } & \multicolumn{3}{|c|}{ Second intermediate } & \multirow{2}{*}{$\begin{array}{l}\text { Below Mohoroviēić } \\
\text { discontinuity }\end{array}$} \\
\hline & & & $\begin{array}{l}\text { Coastal } \\
\text { region }\end{array}$ & $\mid \begin{array}{l}\text { Eastern } \\
\text { region }\end{array}$ & Sierra & \\
\hline$d$ from $\mathrm{P} \ldots \ldots \ldots \ldots$ & $171 / 2$ & $151 / 2$ & 4 & 11 & $30 \pm$ & $\ldots$ \\
\hline$d$ from $\mathrm{S} . . . \ldots \ldots$ & 18 & 15 & 2 & 7 & $30 \pm$ & $\cdots$ \\
\hline$V, \mathrm{~km} / \mathrm{sec} \ldots \ldots \ldots \ldots$ & 5.58 & 6.03 & \multicolumn{3}{|c|}{6.91} & 8.0 \\
\hline$v, \mathrm{~km} / \mathrm{sec} \ldots \ldots \ldots \ldots$ & 3.26 & 3.64 & \multicolumn{3}{|c|}{4.08} & 4.4 \\
\hline$V / v \ldots \ldots \ldots \ldots \ldots \ldots$ & 1.712 & 1.657 & \multicolumn{3}{|c|}{1.694} & 1.811 \\
\hline$\sigma \ldots$ & 0.24 & 0.21 & \multicolumn{3}{|c|}{0.23} & 0.28 \\
\hline$\mu \ldots$ & $2.9 \times 10^{11}$ & $3.8 \times 10^{11}$ & \multicolumn{3}{|c|}{$5.2 \times 10^{11}$} & $6.4 \times 10^{11}$ \\
\hline$k \ldots \ldots$ & $4.6 \times 10^{11}$ & $5.4 \times 10^{11}$ & \multicolumn{3}{|c|}{$7.9 \times 10^{11}$} & $12.6 \times 10^{11}$ \\
\hline р.......... & 2.7 & 2.9 & \multicolumn{3}{|c|}{3.1} & 3.3 \\
\hline
\end{tabular}

TABLE 3

Apparent Velocities, Intercept Times $a$, and Other Frequently Used Quantities All data refer to southern California. Values in parentheses are given for coastal regions.

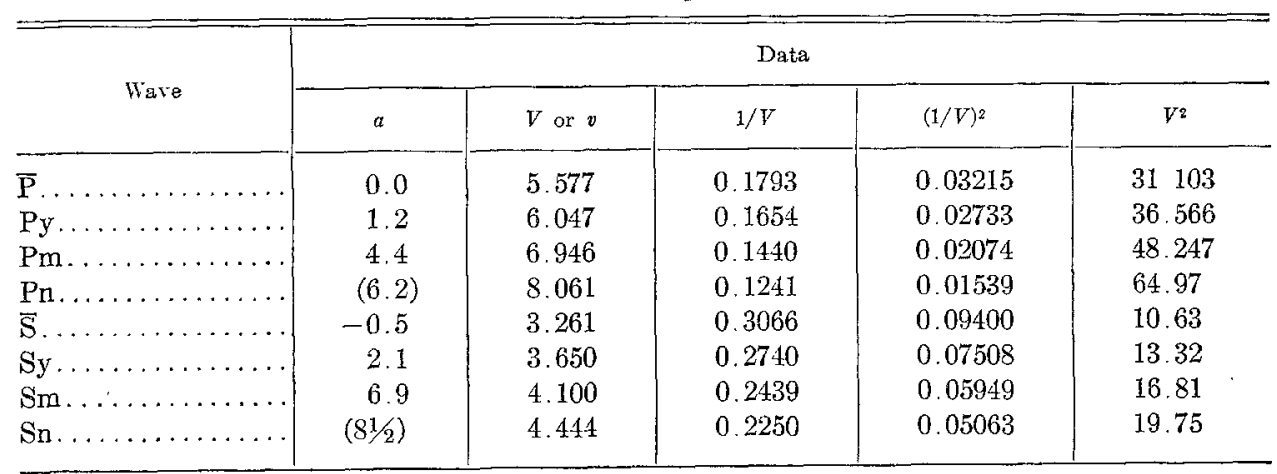


from about $37 \mathrm{~km}$. in the coastal areas to about $44 \mathrm{~km}$. in the eastern mountain region and probably is more than $60 \mathrm{~km}$. in the Sierra Nevada. The thickness of the first two layers seems to be the same throughout the whole area; the total of both combined is about $33 \mathrm{~km}$.

Down to a depth of about $60 \mathrm{~km}$., the velocity seems to increase with depth within each layer as an effect of the increasing pressure. For details, see Gutenberg (1944c). The values of $V$ and $v$ given in table 2 are the true velocities. The apparent velocities are summarized in table 3 .

\section{General Considerations Concerning Amplitudes of Reflected ayd Refracted Waves}

The ground displacement $D$ due to a body wave is given approximately by

$$
D=C T Q \Pi f \sqrt{\frac{\left|d \cos i_{h} / d \Delta\right|}{\Delta \cos i_{0}}}
$$

where $C$ depends on the energy of the shock and the units used, $T=$ period, $i_{h}$ and $i_{0}$ are angles of incidence at the source and surface respectively, $\Delta=$ epicentral distance. $\Pi f=$ product of all factors $f$ which are the square roots of the ratio of the reflected or refracted to the incident energy at each discontinuity encountered by the wave; for details see Gutenberg (1944b), which contains characteristic values of $f$ as well as of $Q$-the ratio between ground displacement (horizontal or vertical) and incident amplitude.

In general, there are three major factors which determine the relative amplitudes of the various waves in a seismogram at a given distance: $C T, \Pi f$, and $\left(d \cos i_{h} / d \Delta\right)$. The first depends on the original energy of the wave; the second indicates the loss of energy at reflections and refractions; the third, the zone on the earth's surface which received a given small fraction of the original energy. Of course, the other quantities cannot be neglected, but usually their differences are relatively smaller.

Aside from the magnitude of the shock, $C T$ depends on the type of wave- $\mathrm{P}, \mathrm{SH}$, or SV; the $\mathrm{S}$ waves start out with more energy than the $\mathbf{P}$ waves (see next section). Usually, $f$ is near unity for refracted waves of the same type as the incident wave, and also for reflected waves of the same type if there is no refracted wave of the same type ("total reflection"). The following rules (with exceptions) may serve as a guide in considering the various possible reflected and refracted waves in seismograms of near-by shocks.

1. If a wave starts out as a $\mathrm{P}$ wave, at a reflection or refraction at an internal discontinuity, usually too little energy is transmitted into an $\mathrm{S}$ wave to produce an outstanding phase in the seismogram. However, an original $\mathrm{S}$ wave may lose more than 90 per cent of its energy at a reflection or refraction into a $\mathrm{P}$ wave, and yet, under favorable circumstances, may produce an impulse exceeding those in the direct $\mathrm{P}$ waves.

2. In waves reflected at internal discontinuities, the resulting amplitudes are often relatively small at the shorter distances, then increase when the critical angle for total reflection is approached, but decrease later as $\left(d \cos i_{h} / d \Delta\right)$ is decreasing rather rapidly when the angle of incidence of the reflected wave approaches $90^{\circ}$; this latter decrease is most rapid for a change from an incident $\mathrm{S}$ wave into a reflected $\mathrm{P}$ wave. 
3 . In reflections at the surface of the earth, the angles of incidence are usually such that most of the energy of an incident $\mathrm{P}$ wave is reflected into $\mathrm{S}$, and vice versa.

Aside from these rules, there are other reasons which sometimes make it unnecessary to discuss certain combinations in the present paper. The distances at which some of the waves arrive are beyond the range discussed here; examples are $\overline{\mathrm{P} S n}$, PySn, PnSn (see, besides, rule 1). Certain other combinations are impossible since the sine of the angle of incidence of the reflected or refracted wave would be always greater than 1.

It should be pointed out that all calculations are made on the assumption that the energy flow at the source does not depend on the direction; this is certainly incorrect, but, on the average, effects of the mechanism of a shock are small as compared with other quantities involved in the calculation. Since generally the logarithm of the amplitudes is used in the present paper, differences amounting to a factor 2 in the amplitudes are "within the limits of error." The effect of variation of energy with azimuth is expected to be especially great when comparing $\mathrm{P}$ and $\mathrm{S}$ waves starting in about the same direction. Other errors may be introduced by the use of measurements from phases due to aftershocks or affected by complications along the wave path.

\section{The Amplitudes of the Direct Waves and the Ratio $\mathrm{S} / \mathrm{P}$}

Amplitudes of the direct waves have been used to investigate the change of wave velocity with depth (Gutenberg, 1944c). From all observations there were calculated the horizontal trace amplitudes which would have been recorded at the given distance by a standard Wood-Anderson torsion seismograph (magnification 2,800, free period 0.8 sec., damping constant 0.8 ) in a shock of magnitude 5 of the Richter magnitude scale. This procedure is followed throughout the present paper. A seismogram in which all phases were recorded with these amplitudes at a given distance is called "standard seismogram." This is for reference purposes only; no torsion seismograph can register on a single record the total horizontal components of the $\mathrm{P}, \mathrm{SV}$, and SH waves.

Logarithms of the amplitudes of the major phases in a standard seismogram (from Gutenberg, 1944c) are reproduced in table 4 . In addition, it was found that, for initial $P$ waves in standard seismograms, $\log C T$ in equation (1) has approximately the value 2.0 , if $\Delta$ is measured in $\mathrm{km}$., and $(d \cos i / d \Delta)$ per $100 \mathrm{~km}$. As records of horizontal components only are used, $Q$ bas to be taken for the horizontal component, that is, the values for $u$ in figure 3 of Gutenberg (1944b) have to be used.

The ratio of $\mathrm{S} / \mathrm{P}$ in the standard seismogram depends on the original ratio of the energies going into $\mathrm{P}$ and $\mathrm{S}$ waves, the difference in the paths and in the values of $f$ (which both are small), and on the difference in $Q$ (eq. 1). For calculations of amplitudes, we need the original ratio of the energies entering into $P, S V$, and $S H$. To find them, in addition to $S / P$, we must know the ratio of the recorded $S V / S H$. This may be investigated either by using vertical components, which theoretically record only SV, but not SH, or by using seismograms corresponding to shocks originating nearly in the azimuth of one of the two horizontal instruments (usually $\mathrm{N}$ or $\mathrm{E}$ or $\mathrm{S}$ or W). To a first approximation it may be assumed that the component recording 
the movement in the direction of the source responds to SV only; the other, perpendicular, to SH. only. As the constants of the vertical components available are very different from those of the standard torsion seismographs, only the second method

TABLE 4

Logarithms of Trace Amplitudes, in Millimeters, and Amplitude

Ratios in a "STandard Seismogram"

Pm and Sm over coastal (a) and over mountain (b) paths.

\begin{tabular}{|c|c|c|c|c|c|c|c|c|c|c|c|}
\hline \multirow{2}{*}{ Phase } & \multicolumn{11}{|c|}{$\Delta(\mathrm{km})}$. \\
\hline & 50 & 100 & 150 & 200 & 250 & 300 & 350 & 400 & 500 & 600 & 800 \\
\hline $\begin{array}{r}\overline{\mathrm{P}} \ldots \\
\operatorname{Py} \ldots \ldots \\
\operatorname{Pm}(\mathrm{a}) \ldots \\
\quad(\mathrm{b}) \ldots \\
\operatorname{Pn} \ldots \ldots\end{array}$ & $\begin{array}{l}1.5 \\
\ldots \\
\ldots \\
\ldots \\
\ldots\end{array}$ & $\begin{array}{l}1.2 \\
0.5 \\
\ldots \\
\ldots \\
\ldots\end{array}$ & $\begin{array}{c}1.0 \\
0.8 \\
\ldots \\
\ldots . \\
(0.2)\end{array}$. & $\begin{array}{c}0.7 \\
0.6 \\
0.4 \\
(0.6) \\
0.0\end{array}$ & $\begin{array}{r}0.6 \\
0.5 \\
0.0 \\
0.4 \\
-0.3\end{array}$ & $\begin{array}{r}0.5 \\
0.2 \\
-0.6 \\
-0.1 \\
-0.5\end{array}$ & $\begin{array}{r}0.1 \\
0.0 \\
-0.7 \\
-0.5 \\
-0.5\end{array}$ & $\begin{array}{r}0.0 \\
-0.2 \\
-0.7 \\
-0.7 \\
-0.7\end{array}$ & $\begin{array}{r}-0.4 \\
-0.5 \\
\ldots \\
\ldots \\
-1.0\end{array}$ & $\begin{array}{r}\ldots \\
\cdots \\
\cdots \\
\cdots \\
-1.2\end{array}$ & $\begin{array}{c}\ldots \\
\ldots \\
\cdots \\
\cdots \\
(-1.7)\end{array}$ \\
\hline $\begin{array}{l}\overline{\mathrm{S}} \ldots \ldots \ldots \\
\text { Sy } \ldots \ldots \ldots \\
\text { Sm (a) . } \\
\text { Sn ....... }\end{array}$ & $\begin{array}{l}2.4 \\
\ldots \\
\ldots \\
\ldots\end{array}$ & $\begin{array}{l}1.9 \\
1.7 \\
\cdots \\
\ldots\end{array}$ & $\begin{array}{l}1.8 \\
1.5 \\
\ldots .2 \\
1.2\end{array}$ & $\begin{array}{l}1.4 \\
1.3 \\
0.8 \\
1.0\end{array}$ & $\begin{array}{l}1.2 \\
1.2 \\
0.8 \\
07\end{array}$ & $\begin{array}{l}1.1 \\
1.0 \\
0.5 \\
0.3\end{array}$ & $\begin{array}{l}0.7 \\
0.5 \\
0.2 \\
0.2\end{array}$ & $\begin{array}{l}0.6 \\
0.3 \\
0.1 \\
0.1\end{array}$ & $\begin{array}{r}0.3 \\
0.1 \\
\ldots \\
-0.1\end{array}$ & $\begin{array}{l}\cdots \\
\ldots \\
\cdots \\
\cdots\end{array}$ & $\begin{array}{l}\cdots \\
\cdots \\
\cdots \\
\cdots\end{array}$ \\
\hline $\begin{array}{l}\overline{\mathrm{S}} / \overline{\mathrm{P}} \ldots \ldots \\
\mathrm{Sy} / \mathrm{Py} \ldots \\
\mathrm{Sm} / \mathrm{Pm} \ldots \\
\mathrm{Sn} / \mathrm{Pn} \ldots .\end{array}$ & $\begin{array}{l}0.9 \\
\ldots \\
\cdots \\
\ldots\end{array}$ & $\begin{array}{l}0.7 \\
1.2 \\
\ldots\end{array}$ & $\begin{array}{l}0.8 \\
0.7 \\
\ldots \\
1.2\end{array}$ & $\begin{array}{l}0.7 \\
0.7 \\
0.4 \\
1.0\end{array}$ & $\begin{array}{l}0.6 \\
0.7 \\
0.8 \\
1.0\end{array}$ & $\begin{array}{l}0.6 \\
0.8 \\
1.1 \\
0.8\end{array}$ & $\begin{array}{l}0.6 \\
0.5 \\
0.9 \\
0.7\end{array}$ & $\begin{array}{l}0.6 \\
0.5 \\
0.8 \\
0.8\end{array}$ & $\begin{array}{l}0.7 \\
0.6 \\
\ldots \\
09\end{array}$ & $\begin{array}{l}\ldots \\
\cdots\end{array}$ & $\begin{array}{l}\cdots \\
\cdots \\
\cdots \\
\cdots\end{array}$ \\
\hline
\end{tabular}

TABLE 5

Data Concerning $S H / S V$ and $S / P$

$\Delta=$ average distance in $\mathrm{km} . ; n=$ number of observations; error $=$ standard error of the average observed $S H / S V .(S H / S V)_{h}$ refers to the source.

\begin{tabular}{|c|c|c|c|c|c|c|c|c|}
\hline \multirow{3}{*}{ Item for which data are given } & \multicolumn{3}{|c|}{ Data for $\mathrm{S}$ from $\overline{\mathrm{S}}$} & \multicolumn{5}{|c|}{ Data for s from Sy } \\
\hline & \multicolumn{8}{|c|}{$\Delta$} \\
\hline & 45 & 60 & 90 & 120 & 160 & 210 & 310 & 390 \\
\hline$S H / S V$ & 2.0 & 1.4 & 1.9 & 1.7 & 1.0 & 1.2 & 1.0 & 1.6 \\
\hline Error... & 0.3 & 0.3 & 0.2 & 0.5 & 0.1 & 0.1 & 0.2 & 0.1 \\
\hline$n \ldots$ & 9 & 7 & 10 & 3 & 14 & 7 & 8 & 8 \\
\hline$(S H / S V)_{h} \ldots$ & 0.6 & 0.4 & 0.4 & 06 & 0.3 & 0.4 & 0.3 & 0.5 \\
\hline $\log S / P \ldots$ & 0.9 & 0.8 & 0.7 & 1.0 & 0.7 & 0.7 & 0.7 & 0.5 \\
\hline
\end{tabular}

was applied. The first line under the headings of table 5 gives the average observed values for $S H / S V$. The last column $(\Delta=390 \pm \mathrm{km}$.) is taken from shocks 1 to 7 (Owens Valley), all others contain only data from shocks 8 to 50.

The angle of incidence of $\overline{\mathrm{S}}$ increases from about $65^{\circ}$ to about $78^{\circ}$, with an increase of $\Delta$ from 45 to $90 \mathrm{~km}$. The corresponding value for $u$ in $\mathrm{SV}$ decreases from about 0.5 to 0.3 over the same range (Gutenberg, 1944b, fig. 3, b). As $u$ is always 2.0 for 
$\mathrm{SH}$, it follows that at the source (subscript " $h$ ") the ratio $(S H / S V)_{h}$ is about 0.4 . The calculated values, also for $\mathrm{Sy}\left(j=67^{\circ} \pm, u=0.5\right.$ for SV), are given in the fourth line of table 5 . In the last line of table 5 the average values $\log S / P$ are repeated from table 4. As, in general, the recorded $\mathrm{SH}$ exceeds the recorded $\mathrm{SV}$, we may assume that this last line gives the observed $S H / P . u_{P}$ varies between 1.8 and 1.6 over the range of $\Delta$ covered by the table, $\log \left(u_{S H} / u_{P}\right)$ is about 0.1 , and, consequently, at the source the average $\log (S H / P)_{h}=0.6 \pm$. Combining this with $\log (S H / S V)_{h}=$ $-0.4 \pm$, we find $\log (S V / P)_{\hbar}=1.0 \pm$. Thus, for calculations referring to the standard seismograms we have the following approximate values for $C T$ in equation (1).

$$
\text { For P: } \log C T=2.0 \quad \mathrm{SV}: \log C T=3.0 \quad \mathrm{SH}: \log C T=2.6
$$

These values will be used mainly to investigate whether a particular wave may probably be observed. They are approximate only. Aside from the rather small body of data on which they are based, it must be pointed out again that the direction in which the energy leaves the source plays an important role. In an earthquake with prevailing vertical fault movements the ratio $S V / S H$ should be different from that in a shock with mainly horizontal movements. A possible source of systematic error may be contained in the implicit assumption that torsion seismographs record the relatively small horizontal ground displacements in the SV waves of the direct $S$ phases without being influenced by the much larger vertical movements. This may have led to too large a value for $C T$ in the $\mathrm{SV}$ waves. Consequently, not too much weight should be given to the result that more energy seems to have gone into the $\mathrm{SV}$ waves than into $\mathrm{SH}$ waves. The effect on other calculations in the present paper should usually be negligible.

In dealing with the energy (and sometimes with amplitudes), differences in the wave period must be considered. Since the periods in the $\mathrm{S}$ waves are roughly twice those in the $\mathrm{P}$ waves, the $\mathrm{SH}$ waves seem to carry about four times and the $\mathrm{SV}$ waves more than twenty times the energy of the $P$ waves. However, these values give only the order of magnitude of the quantities involved.

\section{Waves Reflected at an Internal Discontinuity}

General remarks. - The travel times $t$ of waves are given by the sum of terms $(d / v \cos i)$, where $d=$ thickness of the individual layer, $v=$ wave velocity (longitudinal or transverse, as the case may be), and $i=$ angle of incidence, supposed to be constant throughout the layer. The corresponding epicentral distance $\Delta$, measured along the surface of the earth, is given similarly by a sum of terms ( $d \tan i$ ). All sums are to be taken from the source to the station.

To a first approximation the amplitudes of the waves are given by equation (1). Serious errors may arise when somewhere along the path the wave is traveling close to a discontinuity in the medium with higher velocity, or when the wave length does not exceed the thickness of the layer. In the first case, the true amplitudes may be considerably larger than the calculated amplitudes; in the second, the result will depend on the special conditions, and the true amplitudes may be either larger or smaller than the calculated.

P38P.- - If the source is at the bottom of the granitic layer, the first group of waves to be considered are those reflected from the lower boundary of the first 
intermediate layer at a depth of $33 \mathrm{~km}$. Four different phases are theoretically possible: P33P, S33S, P33S, and S33P. Travel times and distances of P33P are given by

$$
t=\frac{3.227}{\cos i_{1}}+\frac{4.962}{\cos i_{2}} \quad \Delta=18 \tan i_{1}+30 \tan i_{2} .
$$

The angles of incidence are connected, as in all calculations, by Snell's law. Traveltime curves and observations may be found in figure 1, and seismograms showing

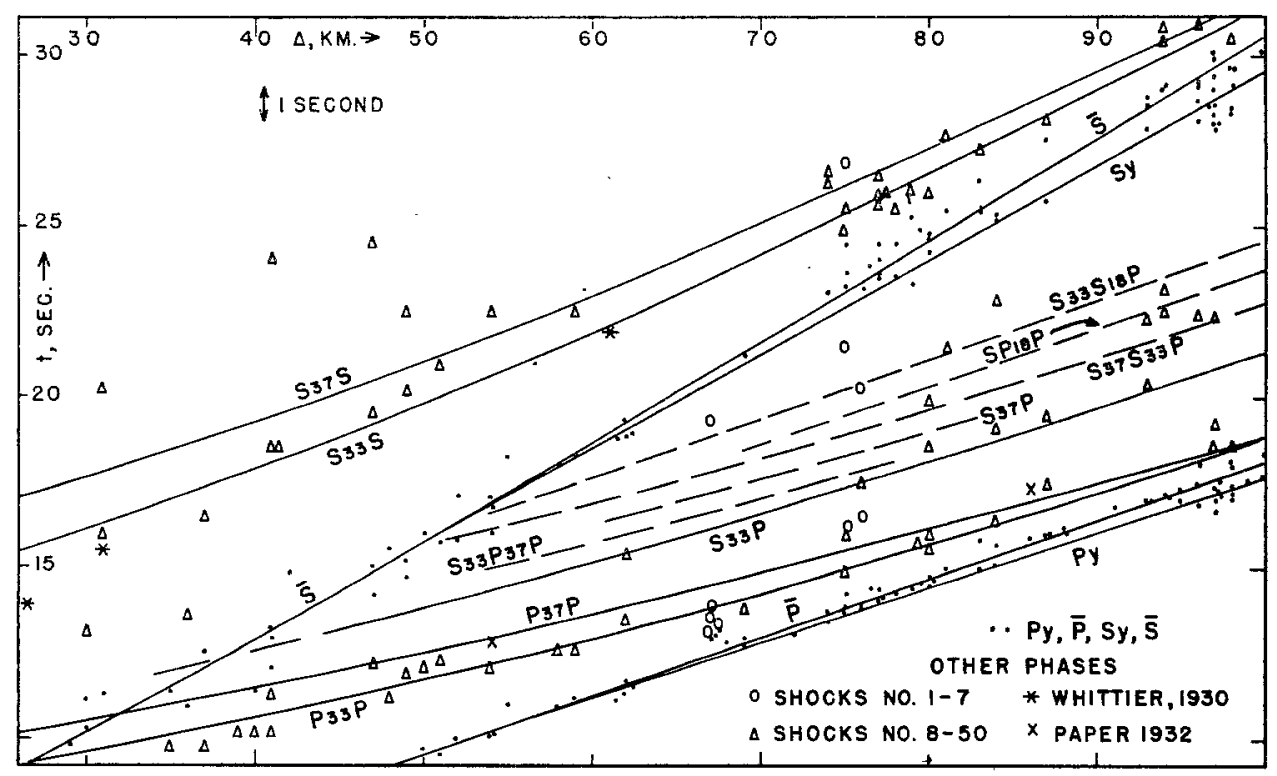

Fig. 1. Calculated and observed travel times for southern California.

this phase in figure 5. P33P should approach Py with increasing $\Delta$ and end at the same point as this phase. Beyond $\Delta=100 \mathrm{~km}$. it is too close to $\overline{\mathrm{P}}$ and $\mathrm{Py}$ to be discriminable. For P33P waves arriving at distances of less than about $40 \mathrm{~km}$. (depending on the curvature of the rays), very little energy is reflected from the discontinuity; in those arriving beyond about $70 \mathrm{~km}$., practically all the original energy remains with this wave. If $\Delta$ increases from 50 to $100 \mathrm{~km}$., $i_{1}$ increases from about $43^{\circ}$ to $58^{\circ}, i_{2}$ from $48^{\circ}$ to $64^{\circ}$, the square root in equation (1) decreases from about 0.15 to about 0.1 , and $Q$ is about $13 / 4$ throughout (Gutenberg, $1944 b$, fig. 3, a). The value of the logarithm of the amplitude in the standard seismogram should increase from about $1 / 2$ at $\Delta=50 \mathrm{~km}$. to $11 / 2$ at $70 \mathrm{~km}$. and should decrease te about $1 \frac{1}{4}$ at $100 \mathrm{~km}$. The fact that the periods of $\mathrm{P} 33 \mathrm{P}$ are, on the average, almost twice those of $\overline{\mathrm{P}}$, should result in an increase in the amplitudes of $\mathrm{P} 33 \mathrm{P}$ by a factor of nearly 2 . On the average, P33P should be about as large as $\mathrm{P}$ (table 4 ) between 70 and $100 \mathrm{~km}$., but smaller at shorter distances, about one-fifth of $\bar{P}$ at $50 \mathrm{~km}$.

The average observed times ( 17 instances) are $0.1 \pm 0.2$ sec. later than the calculated, with standard error of 0.6 sec. for one observation. The logarithm of the 
average observed amplitudes between 50 and $100 \mathrm{~km}$. (reduced to the standard seismogram) is $1.6 \pm 0.2$. This corresponds well with the calculated value of about 1.4, if it is considered that no measurements were made when, owing to relatively small amplitudes, $\mathrm{P} 33 \mathrm{P}$ was not clearly recorded.

S33S.- This is the corresponding S phase. The travel times are given by

$$
t=\frac{5.52}{\cos j_{1}}+\frac{8.22}{\cos j_{2}} \quad \Delta=18 \tan j_{1}+30 \tan j_{2}
$$

It is related to Sy as P33P is to Py. The quantities for the calculation of the amplitudes are approximately the same as for P33P, except that $\log C T Q$ does not exceed

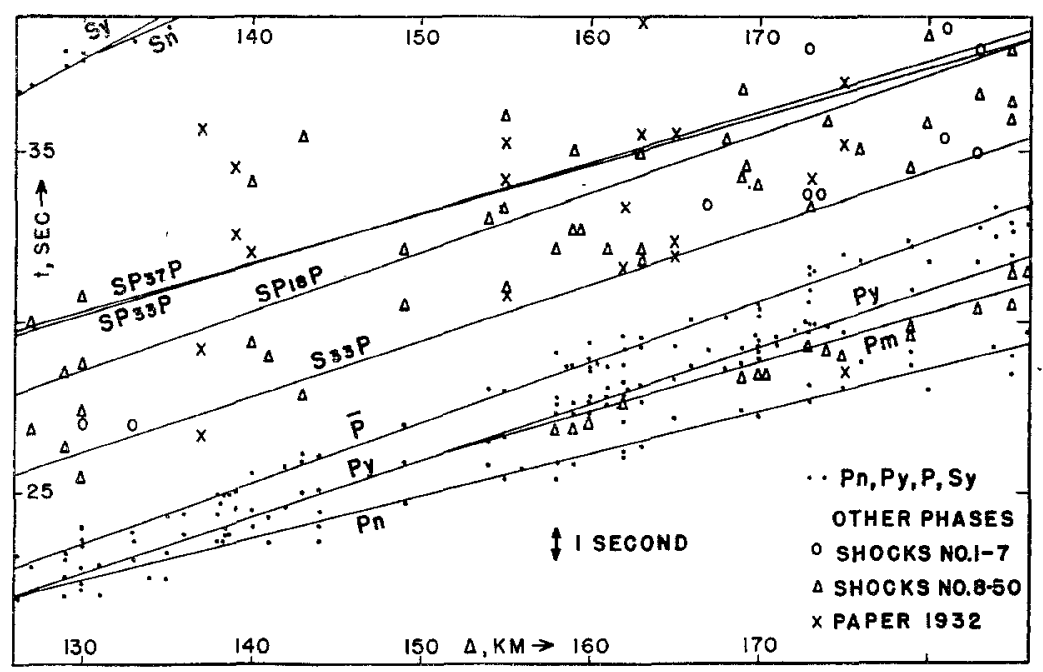

Fig. 2. Calculated and observed travel times for southern California.

2.7 for SV and is 2.9 for SH, as compared with 2.2 for P33P. Thus, it is to be expected that the SH component of S33S should be larger than the SV component, and that $\log$ S33S should be about 0.7 greater than $\log$ P33P. On the average, for epicentral distances between about 60 and $100 \mathrm{~km}$., S33S should be about as large as or slightly larger than $\overline{\mathrm{S}}$.

S33S was first observed by Wood and Richter (1931; "i $\mathrm{i}_{2}$ " in fig. 3, p. 195), who identified it correctly as a reflected $S$ phase. For the reflecting surface, they found a depth of only $24 \mathrm{~km}$., assuming $h=13 \mathrm{~km}$. and a velocity of $3.25 \mathrm{~km} / \mathrm{sec}$. down to the reflecting surface, both now known to be too small. Besides, the arrival time of S33S at Pasadena seems to have been rather early; under the present assumption it is $1 / 2$ sec. below the calculated curve (fig. 1). At the other stations, this difference is only $3 / 4$ sec. (Mount Wilson) and $1 / 4$ sec. (Riverside). Small errors in the location of the epicenter and origin time may have contributed to the result, as well as local effects. It also should be noted that the impulse at Pasadena is rather large for the distance of about $27 \mathrm{~km}$. S33S is frequently recorded in the seismograms investigated in the present paper.(fig. 5); the observed travel times (fig. 1) and the amplitudes fit as well as can be expected. 


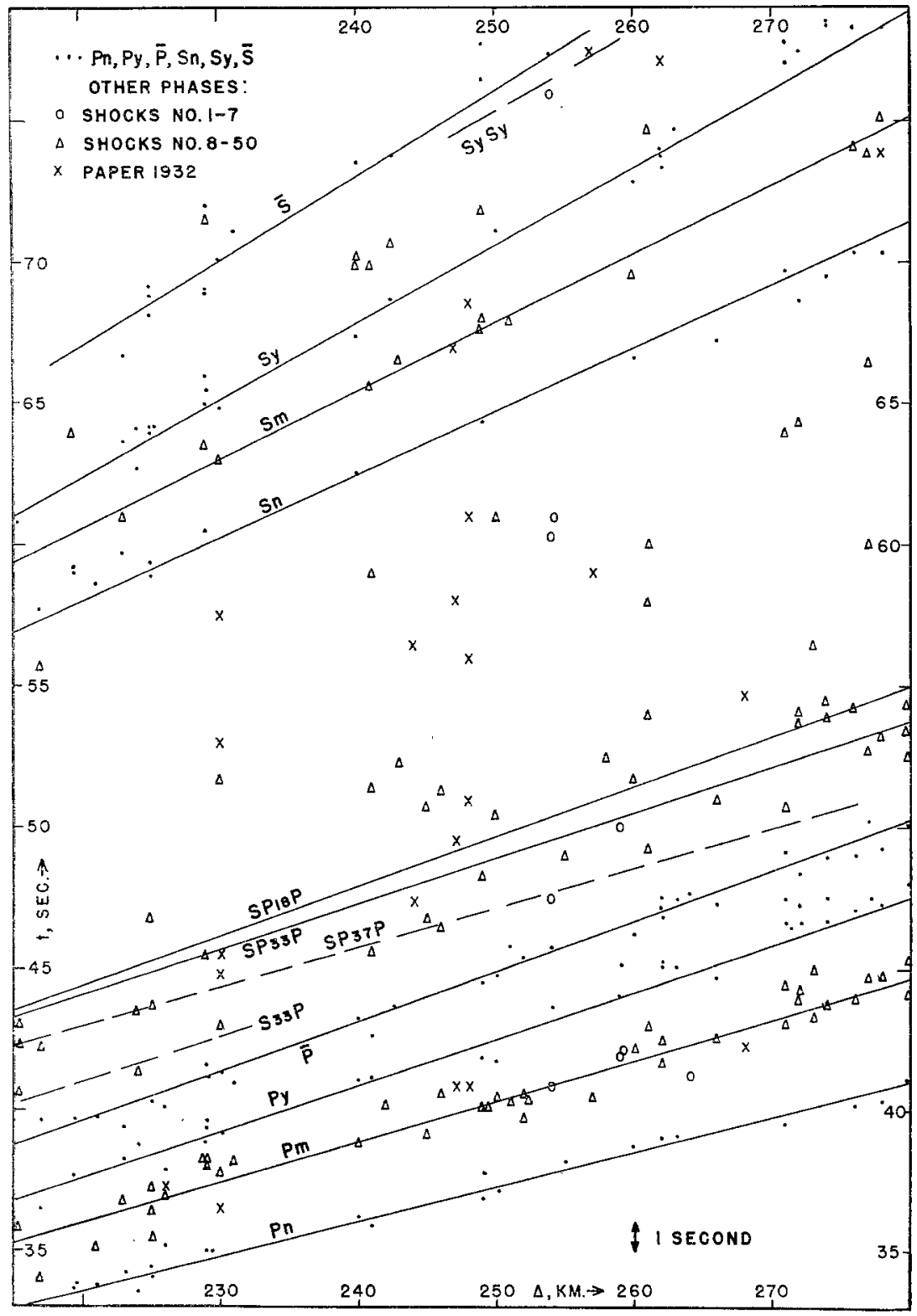

Fig. 3. Calculated and observed travel times for southern California.

S83P.- There are two waves reflected from the discontinuity at $33 \mathrm{~km}$. depth, with a change in wave type: P33S and S33P. P33S need not be considered since it follows $\mathrm{S} 33 \mathrm{P}$ elosely and is rather small (rule 1, general remarks). The travel times of S33P are given by

$$
t=\frac{4.11}{\cos j_{2}}+\frac{2.48}{\cos i_{2}}+\frac{3.23}{\cos i_{1}} \quad \Delta=15 \tan j_{2}+15 \tan i_{2}+18 \tan i_{1}
$$


For the calculation of the amplitudes in the standard seismogram, $\log C T$ is about 3.0 (starting as SV), $\log Q=0.2$, the square root in equation (1) decreases from about 0.14 at $\Delta=30 \mathrm{~km}$. to 0.05 at about $80 \mathrm{~km}$., and 0.01 at about $190 \mathrm{~km}$. The product of $f$ increases from about 0.1 at $\Delta=50 \mathrm{~km}$. to a maximum near 0.2 , as $\Delta$ approaches $100 \mathrm{~km}$, and then decreases again, reaching 0.1 at $\Delta$ beyond $200 \mathrm{~km}$. The calculated logarithm of the trace amplitude is between 1 and $1 \frac{1}{4}$ at distances from 30 to $140 \mathrm{~km}$, and decreases beyond there. Thus, the amplitude of $\mathrm{S} 33 \mathrm{P}$

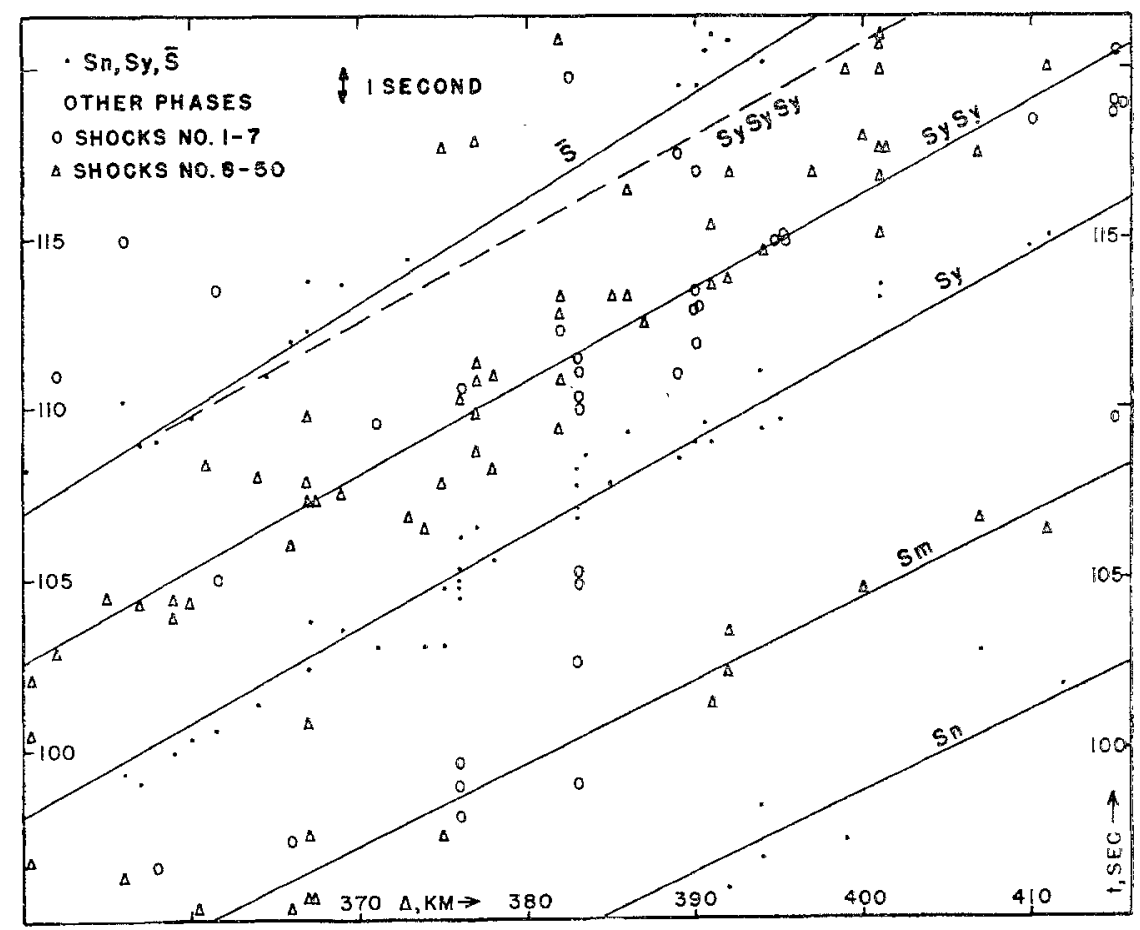

Fig. 4. Calculated and observed travel times for southern California.

recorded by horizontal seismographs at distances between about 75 to $150 \mathrm{~km}$. should be of the same order of magnitude as that of $\overline{\mathrm{P}}$ (table 4), but smaller at shorter as well as longer distances. $\mathrm{S} 33 \mathrm{P}$ should end at about $\Delta=200 \mathrm{~km}$. (end of Py at about $300 \mathrm{~km}$., additional part from surface to depth of $18 \mathrm{~km}$. corresponds to about $40 \mathrm{~km}$. in $\Delta$; maximum horizontal distance of the longitudinal part of S33P about $1 / 2(300+40)=170 ; \mathrm{S}$ part corresponds to about $\Delta=20 \mathrm{~km}$.). This result (fig. 3 ) and also the observed amplitudes (fig. 6, a) and travel times (figs. 1 and 2) agree with observations. $\mathrm{S} 33 \mathrm{P}$ is one of the several rather strong phases which frequently produce an almost continuous group of waves following $\bar{P}$ within a few seconds of each other, at distances from about 70 to beyond $200 \mathrm{~km}$. (fig. $6, \mathrm{~b}$ ).

Waves reflected from the Mohorovičic discontinuity.-Phases similar to those reflected from the bottom of the first intermediate layer which we have just discussed are to be expected from reflection at the bottom of the second, intermediate layer, the Mohorovičic discontinuity. While the bottom of the first is at approximately 
the same depth of $33 \mathrm{~km}$. everywhere in southern California, the depth of the Mohorovičic discontinuity varies from about $37 \mathrm{~km}$. in the coastal areas to perhaps more than $60 \mathrm{~km}$. under the Sierra Nevada. Consequently we have to expect local variations in travel times for these waves. For the coastal areas, we have the following travel times:

$$
\begin{array}{ll}
\text { P37P: } t=\frac{3.23}{\cos i_{1}}+\frac{4.96}{\cos i_{2}}+\frac{1.15}{\cos i_{3}} & \Delta=18 \tan i_{1}+30 \tan i_{2}+8 \tan i_{3} \\
\text { S37S: } t=\frac{5.52}{\cos j_{1}}+\frac{8.22}{\cos j_{2}}+\frac{1.95}{\cos j_{3}} & \Delta=18 \tan j_{1}+30 \tan j_{2}+8 \tan j_{3}
\end{array}
$$

S97P. - The travel time is found by adding $0.58 / \cos i_{3}+0.98 / \cos j_{3}$ to the times, and $4 \tan i_{3}+4 \tan j_{3}$ to the distances of $\mathrm{S} 33 \mathrm{P}$, equation (5). In general, these waves follow the corresponding wave reflected at a depth of $33 \mathrm{~km}$. by from 1 to 2 seconds (figs. 1,2 ) and are scarcely discriminable from it. They produce an apparent multiplicity of P33P, etc. (fig. 5). Their amplitudes are expected normally to be somewhat smaller than those of the corresponding reflections at $33 \mathrm{~km}$. and must depend on the local conditions as also the distance at which they end. This is similar to what has been found for Pm (table 4).

Reflected waves with change of type at a refraction.-As before, we can neglect waves starting as a longitudinal wave. There is only one kind of wave reflected at a depth of $33 \mathrm{~km}$. which is to be considered here, S33S18P. Its travel times are given by

$$
t=\frac{8.22}{\cos \dot{j}_{2}}+\frac{3.23}{\cos \dot{i}_{1}} \quad \Delta=30 \tan j_{2}+18 \tan i_{1}
$$

It belongs to the later waves in the group following $\overline{\mathrm{P}}$ (figs. 1, 2) and usually cannot be identified individually (fig. 6, b). At $\Delta=100 \mathrm{~km}$., the following approximate quantities are to be introduced in equation (1) for the calculation of the amplitudes: $\log C T=3.0 ; \log Q=0.2 ;$ product of $f$ about $0.1 ;$ change of $\cos i_{h}$ with $\Delta$ about 0.02 per $100 \mathrm{~km} . ; 1 / \cos i_{0}=4$. This gives a logarithm of the trace amplitude for the standard seismogram of about 1.1 ; the wave should have an amplitude of roughly $3 / 4$ that of $\overline{\mathrm{P}}$.

Other waves of this group are S33P37P, S37S33P, S37S18P. All these waves are expected to have amplitudes reaching between $1 / 4$ and $3 / 4$ of $\overline{\mathrm{P}}$ at the optimum distances (order of $80 \mathrm{~km}$.). The first is between S33P and S37P, the second follows S37P (fig. 1); both are members of the group of waves in the "tail" of $\overline{\mathrm{P}}$ (fig. 1). S37S18P is superimposed on the $S$ group at those distances at which its amplitudes are relatively largest, and probably does not stand out except under especially favorable circumstances.

Waves reflected from hypothetical bottom of crystalline crust.-The rapid decrease of amplitudes in Pn and Sn at distances of a few hundred km., and other phenomena, indicate that at a depth of roughly $80 \mathrm{~km}$. there is a change which suggests that the melting point of the material is reached (Gutenberg, 1944c). Waves reflected from the corresponding discontinuity are to be expected. It seems likely that the elastic constants and the density in the glassy state are smaller than in the crystalline material by about the same percentage, resulting in roughly the same wave velocities in both. 


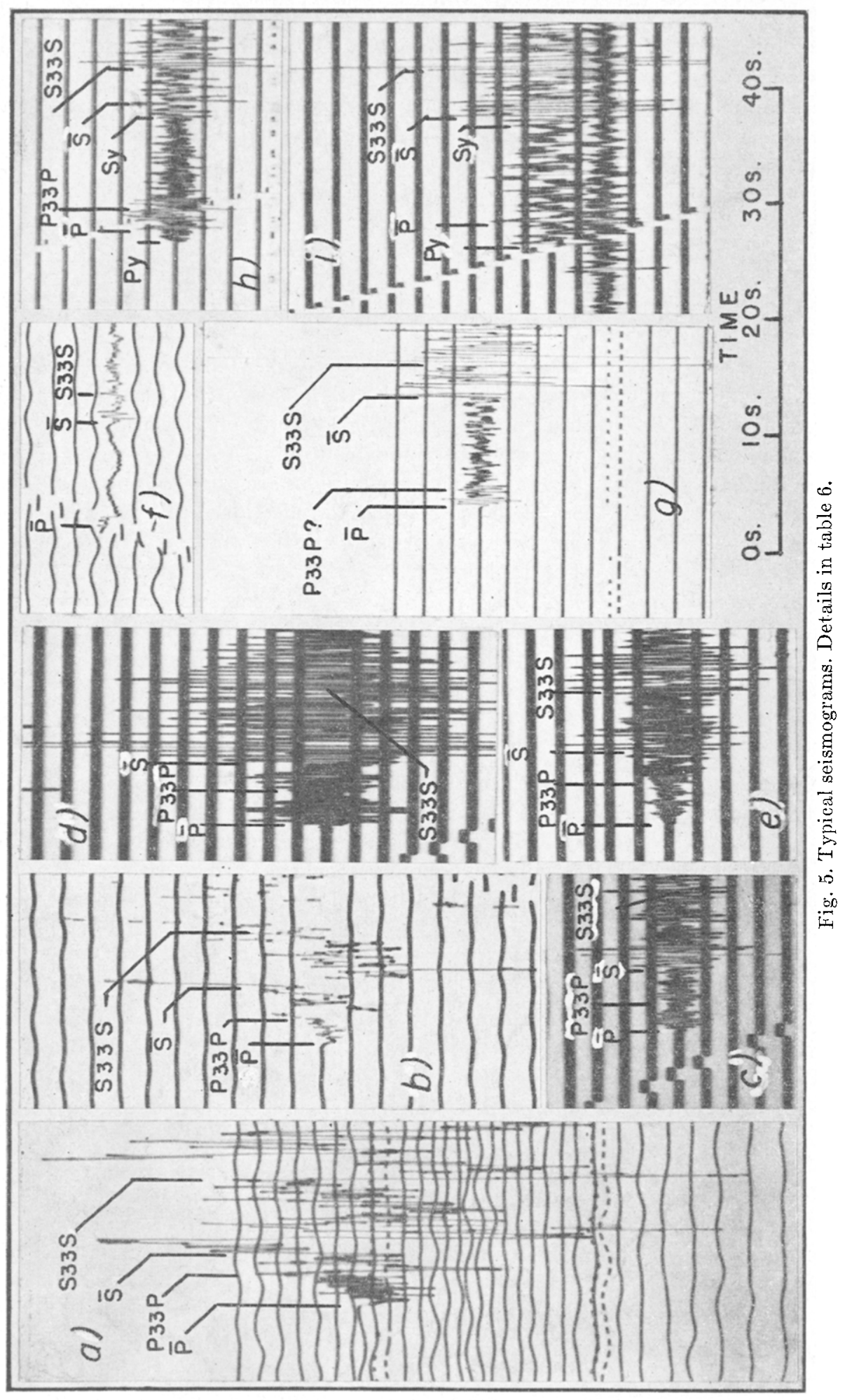


As the accurate depth of the discontinuity is not known, no exact travel times for the reflected waves can be calculated. However, the errors decrease with distance, and for epicentral distances beyond $200 \mathrm{~km}$. cannot be significant if the discontinuity is not too far from the assumed depth of $80 \mathrm{~km}$. The most prominent reflected waves

\section{TABLE 6}

\section{Data Concernntag Figdres 5 and 6}

Instruments: $\mathrm{A}=$ standard, $\mathrm{B}=$ long-period Wood-Anderson torsion seismograph; $Z=$ shortperiod Benioff vertical. Azimuths are measured at epicenter from north toward east.

\begin{tabular}{|c|c|c|c|c|c|c|}
\hline $\begin{array}{l}\text { Fig. } \\
\text { no. }\end{array}$ & $\begin{array}{l}\text { Shock } \\
\text { no. }\end{array}$ & $\begin{array}{c}\text { Region of epicenter } \\
\text { (Details: Gutenberg, 1943c) }\end{array}$ & Station & $\begin{array}{l}\text { Instr., } \\
\text { comp. }\end{array}$ & $\begin{array}{l}\text { Distance, } \\
\mathrm{km} .\end{array}$ & $\begin{array}{l}\text { Azimuth, } \\
\text { deg. }\end{array}$ \\
\hline $5 \mathrm{a}$ & 25 & Inglewood fault. & Pasadena & $\mathrm{B} ; \mathrm{E}-\mathrm{W}$ & 41 & 0 \\
\hline $5 b$ & 21 & Inglewood fault. & Pasadena & $\mathrm{B} ; \mathrm{E}-\mathrm{W}$ & 47 & 10 \\
\hline $5 c$ & . & Three aftershocks & & & & \\
\hline $5 d$ & . & of no. 26 & Mount Wilson & $A ; E-W$ & $50 \pm$ & $\cdot 5 \pm$ \\
\hline $5 \mathrm{e}$ & . & Inglewood fault & & & & \\
\hline 5 f & 34 & Elsinore........ & Pasadena & $\mathrm{B} ; \mathrm{E}-\mathrm{W}$ & 75 & 310 \\
\hline $5 \mathrm{~g}$ & 28 & Riverside........ & Pasadena & $\mathrm{A} ; \mathrm{N}-\mathrm{S}$ & 77 & 275 \\
\hline $5 \mathrm{~h}$ & 41 & Little San Bernardino Mts.. & Riverside & $\mathrm{A} ; \mathrm{N}-\mathrm{S}$ & 97 & $270^{\circ}$ \\
\hline $5 \mathrm{i}$ & 40 & Little San Bernardino Mts.. & Riverside & $\mathrm{A} ; \mathbf{E}-\mathrm{W}$ & 97 & 270 \\
\hline $6 a$ & 14 & Tejon Pass.. & Riverside & $\mathrm{A} ; \mathrm{N}-\mathrm{S}$ & 180 & 30 \\
\hline $6 b$ & 9 & Inyokern..... & Riverside & $A ; N-S$ & 185 & 170 \\
\hline $6 \mathrm{c}$ & 9 & Inyokern... & Boulder City & $A ; E-W$ & 260 & 80 \\
\hline $6 \mathrm{~d}$ & 22 & Inglewood fault..... & Fresno & $\mathrm{A} ; \mathrm{N}-\mathrm{S}$ & 360 & 0 \\
\hline $6 \mathrm{e}$ & 2 & Northern Owens Valley. & Santa Barbara & $\mathrm{A} ; \mathrm{N}-\mathrm{S}$ & 364 & 195 \\
\hline $6 \mathrm{f}$ & 48 & Cuyamaca........... & Haiwee & $\mathrm{A} ; \mathrm{E}-\mathrm{W}$ & 375 & 340 \\
\hline $6 \mathrm{~g}$ & 2 & Northern Owens Valley. & Pasadena & $\mathrm{A} ; \mathrm{N}-\mathrm{S}$ & 390 & 170 \\
\hline $6 \mathrm{~h}$ & 10 & Boulder City. . . . . . . & La Jolla & $\mathrm{A} ; \mathrm{E}-\mathrm{W}$ & 411 & 215 \\
\hline $6 \mathbf{i}$ & 11 & Ludlow, Mojave Desert. & Tucson & $\mathrm{Z}$ & 577 & 110 \\
\hline
\end{tabular}

to be expected are P80P and S80S. S80P should be near $\overline{\mathrm{P}}$ at distances of about 300 $\mathrm{km}$., and near Py at its end, approaching $400 \mathrm{~km}$, but its amplitudes are expected to be only of the order of one-tenth of these phases.

P80P should approach Pn with increasing distance, and S80S similarly should follow Sn. The time interval P80P-Pn decreases from about $5 \mathrm{sec}$. at $\Delta=100 \mathrm{~km}$. to $3 \mathrm{sec}$. at 250 and $2 \mathrm{sec}$. at about $450 \mathrm{~km}$; the corresponding values for S80S-Sn are between twice and three times these figures. At $\Delta=150 \mathrm{~km}$., both reflected waves scarcely exceed one-tenth of the preceding direct phases. Their amplitudes decrease with distance much more slowly than those of the direct waves, and at $\Delta=800 \mathrm{~km}$. both may have amplitudes of the same order of magnitude as the respective preceding $\mathrm{Pn}$ and $\mathrm{Sn}$ waves. Under favorable conditions they may be taken for the phases "Px" (to be discussed later) and "Sx." There is little hope that P80P or S80S may be used to prove the existence of the hypothetical discontinuity or to determine its actual depth. 


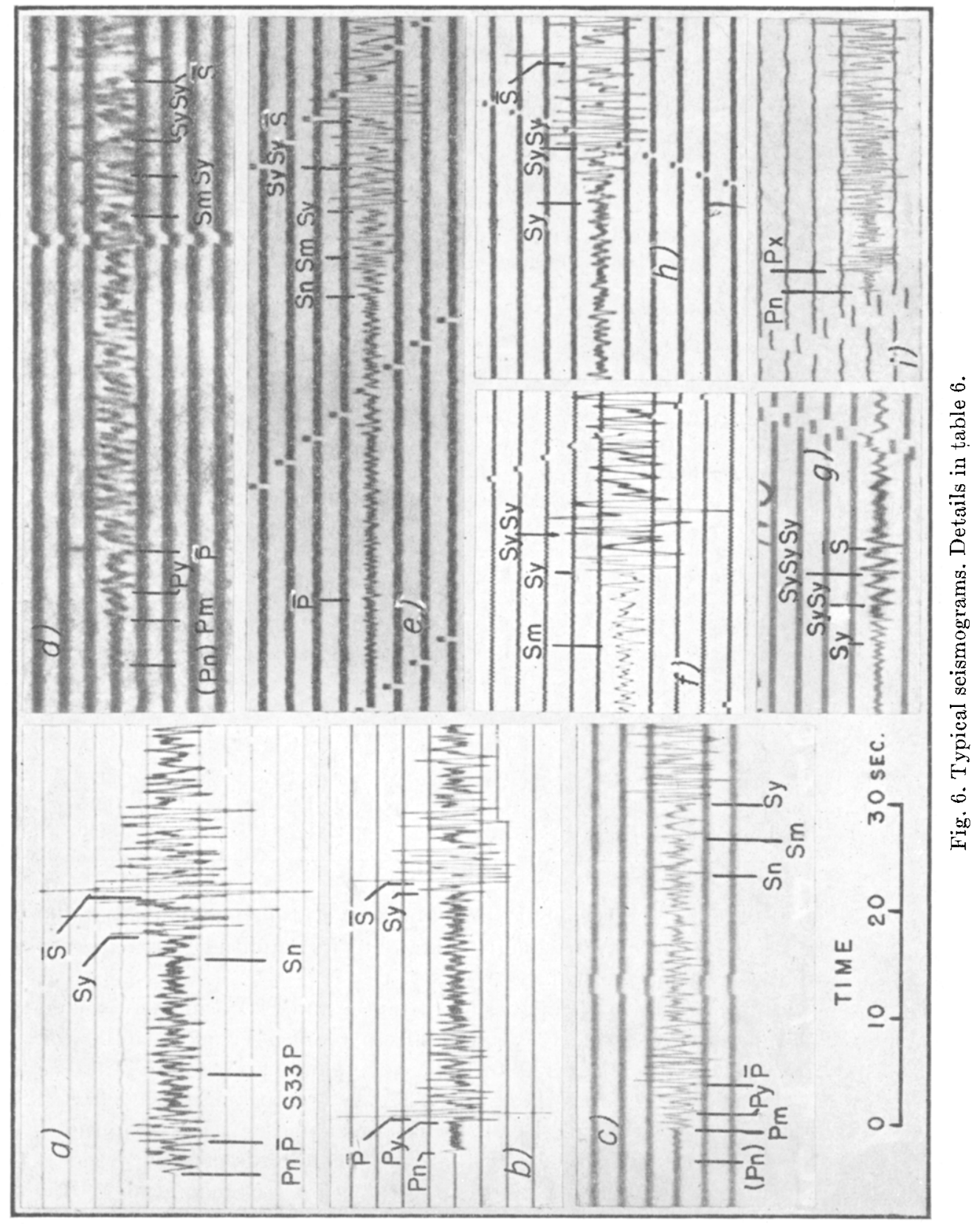




\section{Waves Reflected at the Surface of the Earti}

Waves traveling in the granitic layer only.-If the source is at the bottom of the granitic layer, $\overline{\mathrm{PP}}$ and $\overline{\mathrm{SS}}$ consist of a single point each, at three times the distance at which the corresponding direct wave ends. $\overline{\mathrm{PS}}$ is impossible $(\sin i>1) . \overline{\mathrm{SP}}$ should follow $\overline{\mathrm{P}}$ after about 41/2 sec. at distances between 100 and $300 \mathrm{~km}$., but should be much smaller than $\overline{\mathrm{P}}$, since $(d \cos j / d \Delta)$ is only of the order of 0.001 , and $f$ decreases toward zero with increasing distance.

Reflected longitudinal waves.--There seem to be no longitudinal waves reflected at the surface which are large enough to be clearly recorded in seismograms of local shocks under usual conditions. Those starting with $\mathrm{P}$ which carry enough energy to be discriminable are of the type PSn and emerge at distances beyond those discussed in the present paper. PyPy has an angle of incidence of about $67^{\circ}$, and receives little energy at the point of reflection; practically all the energy is reflected into Pysn. This is true, similarly, for $\mathrm{PmPm}\left(i=53^{\circ} \pm\right)$ and $\mathrm{PmSn}$ respectively. $\mathrm{PnPn}$, with an angle of incidence of about $45^{\circ}$, has a factor $f$ of about $1 / 4$ at the point of refiection; its amplitudes would be less than 0.2 of the amplitudes of $\mathrm{Pn}$ at half the distance at which it emerges. It is due to arrive during the later part of the $\mathrm{P}$ group; its amplitudes cannot be expected to exceed noticeably those of the general disturbance of the seismogram, owing to various causes, at its time of arrival.

Reflected transverse waves; general remarks.-The conditions are entirely different for the reflected transverse waves. The angles of incidence at the point of reflection frequently are greater than the critical angle $\left(36^{\circ} \pm\right)$, and all the energy of the arriving SV waves goes into the reflected transverse wave. Reflected SH waves always carry all the incident energy. In all instances of total reflection the resulting wave has roughly one-half the amplitude of the direct wave at half the distance; similarly, a twice reflected wave has about one-third the amplitude of the direct wave at one-third of the distance. All quantities are roughly the same, except for $\Delta$ and $(d \cos i / d \Delta)$; in SS, the latter has a value of about one-half that for $\mathrm{S}$ at half the distance.

The travel-time difference between an SS wave and the corresponding $S$ wave is given by

$$
\delta=\tau+\frac{h \cos j_{1}}{v_{1}}
$$

where $\tau=$ intercept time of the S wave. SSS follows SS by the same amount $\delta$.

$S y S y$ and $S y S y S y$.-The intercept time of Sy relative to the "origin time of $\overline{\mathrm{S}}$ " is 2.6 sec., and 2.1 sec. relative to that of $\bar{P}$. The effect of the faulting process on the arrival time of $\mathrm{Sy}$ is probably smaller than on $\overline{\mathrm{S}}$, for which it is about 0.5 sec. (Gutenberg-Richter, 1943). If we assume $0.3 \mathrm{sec}$. for Sy $\left(j=67^{\circ}\right)$, we have $\tau=2.4$ sec. Taking $h=18 \mathrm{~km} . j_{1}=67^{\circ}$, we find from (9) that SySy should follow Sy after about 4.6 sec., and SySySy should arrive about 9.2 sec. after Sy. At $\Delta=200 \mathrm{~km}$. the amplitudes of SySy should be about equal to those of Sy, at $300 \mathrm{~km}$. they should be slightly larger than those of Sy, and from $\Delta=400$ to $500 \mathrm{~km}$., SySy as well as SySySy should have roughly four or five times the trace amplitudes of Sy. The 


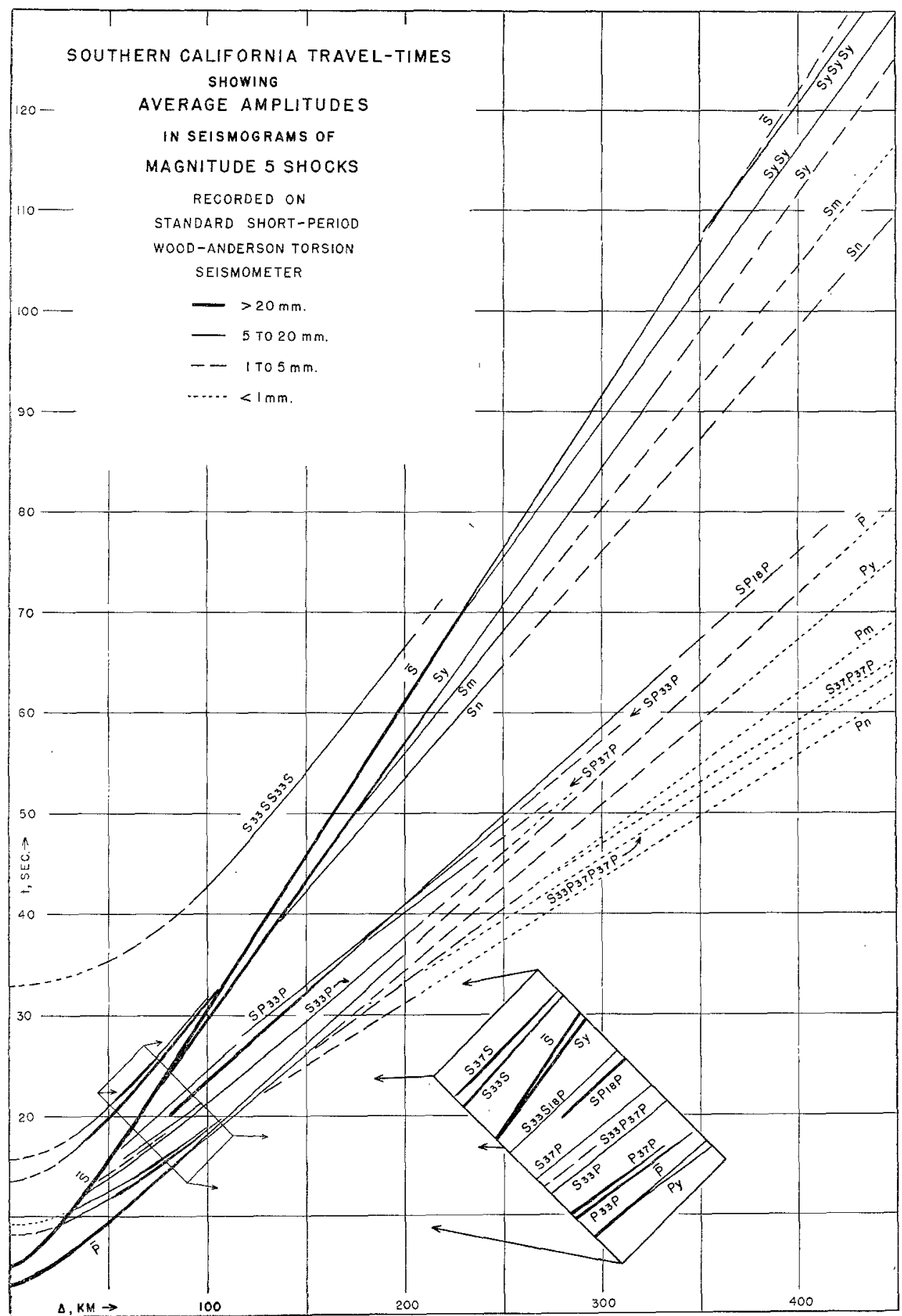

Fig. 7. Calculated travel-time curves for southern California. 
observations (figs. 4, 6, d-h) confirm the theoretical results in every respect. SySy was more frequently measured than Sy at distances beyond $400 \mathrm{~km}$.

Observed time intervals are given in table 7. The data for the fourth line were taken from Gutenberg (1932). The resulting value $\delta=4.4$ sec. may be used to calculate $h$, the depth of focus, from (9). Using $\tau=2.4$ sec., as before, the result is $h=17 \mathrm{~km}$. This can be considered a good check, as an error in the assumed $\tau$ by $0.1 \mathrm{sec}$. (or a similar error in $\delta$ ) changes the resulting $h$ by $0.8 \mathrm{~km}$. On the other hand, assuming that the apparent velocity of the waves is $3.65 \mathrm{~km} / \mathrm{sec}$. as found for Sy, the observed travel times of Sysy permit the calculation of $\tau+\delta$, while those of SySySy give $\tau+2 \delta$. The combination of both results in $\tau=2.1 \pm 1.2$ (relative to

TABLE 7

Time Differences SySy-Sy ( $\delta$ In seconds) and SySySy-Sy $(2 \delta)$

$n=$ number of observations

\begin{tabular}{|c|c|c|c|c|c|c|}
\hline \multirow{2}{*}{ Shock nos. } & \multicolumn{3}{|c|}{ SySy - Sy } & \multicolumn{3}{|c|}{ SySySy - Sy } \\
\hline & Range of $\Delta$ & $n$ & $\delta$ & Range of $\Delta$ & $n$ & $2 \delta$ \\
\hline $8-50$. & $284-400$ & 41 & $4.5 \pm 0.7$ & $387-473$ & 12 & $8.5 \pm 1.0$ \\
\hline $8-50$. & $400-849$ & 24 & $4.6 \pm 0.7$ & $544-818$ & 10 & $9.2 \pm 0.8$ \\
\hline $1-6 \ldots$ & $376-537$ & 24 & $4.1 \pm 0.8$ & $390-932$ & 5 & $8.8 \pm 1.0$ \\
\hline$(1932)$ & $257-606$ & 7 & $4.5 \pm 1.7$ & $\ldots \ldots$ & . & $\ldots \ldots$ \\
\hline $1-50$ & $284-849$ & 89 & $1.4 \pm 0.7$ & $387-932$ & 27 & $8.8 \pm 0.9$ \\
\hline
\end{tabular}

the origin time of $\overline{\mathrm{P}}$ ) and $\delta=4.4 \pm 1.2 \mathrm{sec}$. Finally, the values of $\delta$ agree within the limits of error among the various regional groups. This indicates that the depth of focus does not differ in the various areas beyond the limits of errors involved in the method.

Other phases of the type SS and SSS.--SmSm should follow Sm after about 10 sec. At distances of less than about $500 \mathrm{~km}$., it arrives later than Sy and may produce an apparent multiplicity of this phase (fig. $6, \mathrm{~h}$ ); its amplitude should be slightly larger than that of Sy at distances between 400 and $500 \mathrm{~km}$.; beyond $500 \mathrm{~km}$., SmSm precedes $\mathrm{Sy}$, but both phases are relatively small. SmSmSm is to be expected in the group of waves produced by $\overline{\mathrm{S}}$ and SySy which have much larger amplitudes.

Equation (9) gives $\delta=12 \pm$ sec. for $\mathrm{SnSn}-\mathrm{Sn}$ beneath the coastal regions of southern California, and more beneath mountain regions. At distances between 600 and $900 \mathrm{~km}$., the recorded SnSn should exceed $\mathrm{Sn}$; beyond $\Delta=400 \mathrm{~km}$., both phases cannot be expected to be observable on torsion seismograph records of shocks of magnitude less than 5 . SnSn possibly was recorded by the short-period Benioff vertical seismograph at Tucson in shocks 8 and 17 (magnitudes 5 and $6, \Delta=762$ and $849 \mathrm{~km} ., \delta=15 \pm$ and $11 \pm$ sec. respectively). It also may explain the observation that shocks in the region of Eureka, recorded at Pasadena ( $\Delta$ about $950 \mathrm{~km}$.), show an $\mathrm{S}$ "usually consisting of two sharp phases about 10 seconds apart, the later having the larger amplitude" (Gutenberg-Richter, 1935, p. 343).

Another phase of the SS type which may be observable is the S33S wave after a reflection at the surface. The most favorable distances for observation are between 
100 and $200 \mathrm{~km}$.; for shorter distances, only part of the original energy goes into S33SS33S, for larger distances it arrives too near to $\overline{\mathrm{S}}$. The travel times are plotted in figure 7. It is a late phase, and normally relatively large amplitudes are found where it is to be expected, but the fact that it is superimposed on other $\mathrm{S}$ phases and surface waves usually makes it impossible to fix any time of beginning.

Waves which have traveled in the granitic layer only, before their reflection at the surface.-The large majority of the possible combinations belonging to this group are expected to have too small amplitudes to be of significance. Those traveling after the reflection in the granitic layer only have been discussed already. Waves having their deepest point within a layer will be discussed in the next section. Hence we have, here, to deal only with waves reflected from the bottom of a layer.

There seems to be no phase in this group beginning with $\mathrm{P}$ large enough to be of importance. PP18P follows $\overline{\mathrm{P}}$, but is much smaller. This is true, too, for PP33P, PP37P, PS18S, etc., which are still later.

For waves starting as $\mathrm{S}$ and continuing as $\mathrm{P}$ waves after reflection at the surface, the conditions are favorable if the angle of incidence at the surface is between about $15^{\circ}$ and $35^{\circ}$. Most of the arriving energy is then reflected into a longitudinal wave. For SP18P this condition, as well as that for practically total reflection at the bottom of the granitic layer, is fulfilled for waves arriving at distances between about 90 and $200 \mathrm{~km}$. (For similar reasons, neither SP18S nor SS18P should be large.) The travel times of SP18P are given by

$$
t=\frac{5.52}{\cos j}+\frac{6.45}{\cos i} \quad \Delta=18(\tan j+2 \tan i)
$$

It is one of the later phases, following $\overline{\mathrm{P}}$ (figs. 1, 2,3) and for most distances so close to othel phases that it cannot be identified individually. Its amplitudes should be of the same order of magnitude as those of $\overline{\mathrm{P}}$. At distances between 100 and $250 \mathrm{~km}$. it is within 1 sec. of the curve " $d$," previously found for southern California shocks (Gutenberg, 1932; figs. 8-10 of that paper show seismograms containing this phase and give characteristic examples of the movement following $\overline{\mathrm{P}}$. However, it should be pointed out that seismograms recorded at Santa Barbara-as usual with stations near the coast--show more vibrations than the other stations, owing to the effect of water-saturated unconsolidated sediments below the station).

Phases similar to SP18P are SP33P and SP37P. Both have amplitudes of the same order of magnitude as $\overline{\mathrm{P}}$, and the first is possibly even larger near $\Delta=150 \mathrm{~km}$. The travel time of SP33P is found by adding $\left(4.96 / \cos i_{2}\right)$ to the value of $t$, and $\left(30 \tan i_{2}\right)$ to that for $\Delta$ in equation (10). For coastal paths, the travel times of SP37P are found by adding, further, $\left(1.15 / \cos i_{3}\right)$ and $\left(8 \tan i_{3}\right)$ respectively. Both phases belong to the group after $\overline{\mathrm{P}}$. Over paths beneath the coastal areas, SP37P should decrease rapidly if $\Delta$ approaches $200 \mathrm{~km}$. As a number of observations fit the calculated curve at distances beyond $240 \mathrm{~km}$. (fig. 3) the paths corresponding to these points were investigated. All points but one were taken from records at Haiwee and belong to paths beneath mountains. The remaining point is from the record of shock 31 (San Bernardino Mountains) at Santa Barbara; the path is mainly under mountain ranges, but the phase may well be one of the freak impulses at Santa Barbara, mentioned above. 
Phases of this group traveling as transverse waves only, seem to be of little importance. SS18S follows $\overline{\mathrm{S}}$ after about 4 sec. at $\Delta=120 \mathrm{~km}$.; the interval decreases to less than $2 \mathrm{sec}$. beyond $200 \mathrm{~km}$. The amplitudes of $\mathrm{SS} 18 \mathrm{~S}$ rarely should reach those of $\overline{\mathrm{S}}$. This is true, too, for phases SS33S and SS37S which follow $\overline{\mathrm{S}}$ closely if $\Delta$ is small and are between SySy and $\bar{S}$ for greater $\Delta$.

Phases which start downward from the source and are reflected when they reach the surface of the earth arrive rather late and lose too much energy to stand out above the rather large disturbance produced by the $S$ waves and the surface waves. A possible exception is S33SS33S, which has been mentioned already. One or the other of such waves may contribute to the movements following the $\overline{\mathrm{S}}$ waves. However, there is a difference between the "tail of $\overline{\mathrm{P}}$ " and the movement following $\overline{\mathrm{S}}$. The former consists mainly of waves which have started out as $\mathbf{S}$ waves and, in spite of loss of energy at reflections and refractions, are of the same order of magnitude as the "direct" $\mathrm{P}$ waves; the movement forming the tail of the $\overline{\mathrm{S}}$ group probably consists largely of surface waves.

\section{Minor Refracted Waves Having Their Deepest Point wrthin a Layer}

General remarks.--Refracted waves traveling along their whole path as P or SV or $\mathrm{SH}$ have been discussed previously. At discontinuities little energy is refracted from an arriving $P$ wave into SV, and vice versa. Consequently, waves in which an original $\mathrm{P}$ wave is refracted into an $\mathrm{S}$ wave are too small for observation, and only waves starting with SV and arriving earlier than S need to be considered. Another limitation arises from the fact that at the deepest point the sine of the angle of incidence is 1 . No transverse path there is possible, since otherwise $\sin i$ of any longitudinal section would be greater than 1 . Thus, there remain for consideration in the present section only waves starting as $\mathrm{S}$ waves which are transformed into $\mathrm{P}$ waves before they pass through the deepest layer.

S33P33P.-Following the refraction at the discontinuity at $33 \mathrm{~km}$., these waves travel along the same path as Pm. Their travel times and distances differ from those of $\mathrm{Pm}$ by

$$
15\left(\frac{1}{v_{2} \cos j_{2}}-\frac{1}{V_{2} \cos i_{2}}\right) \text { and } 15\left(\tan j_{2}-\tan i_{2}\right)
$$

respectively. With $\sin j_{2}=0.5256$, sin $i_{2}=0.8708$, it follows that $t$ is shortened by 0.22 sec., and $\Delta$ by $17.2 \mathrm{~km}$. This difference in distance corresponds to a difference of 2.48 sec. in travel time of Pm. Consequently, S33P33P should follow Pm by $2.48-0.22=2.3 \mathrm{sec}$. Up to almost $300 \mathrm{~km}$., it follows closely the larger Py; beyond, it precedes $P y$. In general, its amplitude should be of the same order of magnitude as that of Pm. As this is rather small beyond $\Delta=300 \mathrm{~km}$. (table 4), S33P33P in general is not a conspicuous phase.

S33P37P37P, S37P37P, and Px.--There remain two waves, S37P37P and S33P37P37P. Both have paths coinciding with that of Pn except for the beginning. They start as SV waves and are related to $P n$ in a way similar to the relation of S33P33P to Pm. In the first the transition from S to P occurs at the discontinuity at $33 \mathrm{~km}$. depth, in the second at the Mohorovicić discontinuity (depth $37 \mathrm{~km}$. beneath the coastal areas, elsewhere greater). For S33P37P37P the time differences 
relative to $P n$ are given by $(11)$, but now $\sin j_{2}=0.4526$, $\sin i_{2}=0.7498$; the travel time of S33P37P37P exceeds that of Pn by 0.86 sec., the corresponding distance is shortened by $9.38 \mathrm{~km}$. It should follow Pn after $1.16+0.86=2.0 \mathrm{sec}$.

The angle of incidence of $S$ at the depth of $33 \mathrm{~km}$. is about $27^{\circ}$. The corresponding value of $f$ (eq. 1) is about 0.1 , and ( $I f$ ) for S33P37P37P about one-tenth of that for $\mathrm{Pn} ; C T$ is about 10 times that of $\mathrm{Pn}$, the square root in equation (1) about 0.8 of that for $\mathrm{Pn}$, and $Q$ is about the same for both. Consequently, on the average, S33P37P37P should be slightly smaller than Pn.

For S37P37P, an additional increase in travel time results from the transverse path in the second layer. Since the thickness of this layer depends on the locality, the time interval S37P37P-Pn is expected to depend on the wave path. It should be about $3 \frac{1}{2}$ sec. in the coastal areas, but greater along paths under mountains. For the calculation of the amplitude ratio, about the same factors enter as given for S33P37P37P, except that now ( $\Pi f)$ is somewhat greater. In general, S37P37P should be of the same order of magnitude as Pn. However, all three waves discussed in this section may occasionally have amplitudes exceeding those of the direct wave which they follow, if the mechanism of the shock produces a relatively large amount of shearing energy in the direction in which the original $S$ wave sets out. The two waves following Pn then may have noticeably greater amplitudes than Pn and may be measured as the phase known as "Px."

The wave Px was observed first by V. Conrad and was studied in seismograms of southern California shocks by Gutenberg (1932, p. 23). Its travel times seemed to increase with distance, but it is evident now that some of the Px waves found at shorter distances really were Py waves or other phases. In the study of the present shocks, Px was found occasionally with amplitudes about five times those of Pn (fig. $6, \mathrm{i}$ ), but frequently it could not be detected at all. In 21 records (including 2 with two phases) the time interval Pn-Px was measured and found nine times to be 0.9 to 1.5 sec.; eight times, 1.9 to 2.5 sec.; and six times, 2.9 to $4.0 \mathrm{sec}$. There seems to be no effect of distance (between 367 and $818 \mathrm{~km}$.) on the time of arrival. Some waves of the first group may be due to instances of P80P; some or all of the second group, to S33P37P37P; and those of the last group, to S37P37P. Like Conrad, the author found it difficult to explain $\mathrm{Px}$ as a $\mathrm{P}$ wave refracted through an additional intermediate layer.

\section{CONCLUSIONS}

An attempt has been made to combine an analysis of observed travel times in nearby shocks recorded in southern California with a study of the corresponding amplitudes to afford an interpretation of the seismograms. This leads to a structure above the Mohorovičic discontinuity consisting of a "granitic layer" (frequently below sediments) and two intermediate layers. The bottom of the granitic layer seems to be generally at a depth of about 17 or $18 \mathrm{~km}$., and the foci of earthquakes are in, or close to, this discontinuity without significant local deviations under mountain regions or areas with thick sedimentary layers. The effect of sediments has not been investigated in detail; their individual thickness is usually less than a wave length, and the shorter waves available from artificial explosions are required for their study. Since the wave velocity increases rather rapidly with depth in the 
uppermost two or three kilometers, and-for example, in old consolidated sediments - may even slightly surpass the wave velocity in granite, the travel times are affected by the sediments by a few tenths of a second at most. Rather large local variations in amplitudes are found, but a more closely spaced network of stations is required to permit a more exact determination of epicenters and focal depths, as well as the interpretation of the local differences in structure.

The first intermediate layer, too, shows remarkably small local variations. It seems to be about 15 kilometers thick everywhere in the region under investigation. Contrasting with this, the thickness of the second intermediate layer increases from a few kilometers in the coastal areas to roughly 30 kilometers under the Sierra Nevada. Table 2 contains data on the physical constants in these layers and immediately below.

The travel times, as well as the amplitudes of the recorded waves, are well explained on the basis of this structure. Figure 7 shows calculated travel times of major phases. There are many more small phases to be expected; some of them may be found in figures 1-4. No major observed travel-time curve remains unexplained; individual larger unidentified waves may be due to complications in the mechanisms of the shock or to local idiosyncrasies of the structure along the wave path. On the other hand, the relatively small standard errors in the observed travel times indicate a much more uniform structure (except for the second intermediate layer) and focal depth than was expected.

The progress and higher accuracy available in the present paper relative to the results obtained in 1932 were made possible under extension of the coöperative program of research by the Carnegie Institution of Washington and the California Institute of Technology. They are mainly due to the installation of short-period Benioff seismometers at all stations of the local group and at Tucson and Berkeley; the use of better chronometers, controlled by six time signals every day; and the much greater body of data now available, including those from the stations at Fresno (since 1936) and the Lake Mead group (since 1938). Further revisions and additions will certainly be possible by using records of future shocks. The recent installation of Benioff short-period seismographs at three stations of the Lake Mead group and at Shasta Dam will aid materially in more accurate determination of the elements of shocks in the eastern part of southern California and the Sierra Nevada region. But the attack on many problems concerning local structure will be really promising only if a denser network of stations becomes available. 
EPSTEIN, P.

\section{LIST OF REFERENCES}

1930. "Reflection of Waves in an Inhomogeneous Absorbing Medium," Proc. Nat. Acad. Sci., $16: 627-637$.

GUTENBirg, B.

1932. "Travel-Time Curves at Small Distances and Wave Velocities in Southern California," Gerlands Beitr. z. Geophys., 35:6-50.

1943a. "Seismological Evidence for Roots of Mountains," Bull. Geol. Soc. Am., 54:473-498.

19136. "Earthquakes and Structure in Southern California," Bull Geol. Soc. Am., 54:499-526.

1944a. "Travel Times of Principal P and S Phases over Small Distances in Southern California," Bull. Seism. Soc. Am., 34:13-32.

1944b. "Energy Ratio of Reflected and Refracted Seismic Waves," Bull. Seism. Soc. Am., 34:85-102.

1944c. "Variations in Physical Properties within the Earth's Crustal Layers," Am. Jour. Sci., Daly Volume, in press.

Gutenderg, B., and C. F. Richter

1935. "On Seismic Waves (Second Paper)," Gerlands Beitr. z. Geophys., 45:280-360.

1943. "Apparent Origin Time of $\overline{\mathrm{S}}, "$ Bull. Seism. Soc. Am., 33:269-279.

WOOD, H. O., and C. F. RichteR

1931. "Recent Earthquakes near Whittier, California," Bull. Seism. Soc. Am., 21:183-203.

California Institete of Technology

Pasadena, California

(Balch Gradtate School of the Geological Sciences, Contribution no. 360.) 